Ulf Kessler · Zacharias Zachariou · Dorothea Raz

Johannes Poeschl · Otwin Linderkamp

\title{
Effects of Intralipid infusion on hemorheology and peripheral resistance in neonates and children
}

Accepted: 15 October 2004 / Published online: 13 January 2005

(C) Springer-Verlag 2005

\begin{abstract}
Deleterious microcirculatory effects of Intralipid (IL) infusion may be caused by hemorheological or vascular effects. The aim of this investigation was to study vascular and hemorheological effects of IL in preterm and fullterm neonates and children. Ten preterm newborns, 10 fullterm neonates, and 10 children received an initial infusion of IL $(0.6 \mathrm{~g} / \mathrm{kg})$ over $4 \mathrm{~h}$. Calf blood flow (venous occlusion plethysmography), blood pressure (Dinamap), whole blood and plasma viscosity (capillary viscometer), red blood cell deformability (rheoscope), and erythrocyte aggregation (aggregometer) were measured before and after administration of IL. Plasma triglyceride levels showed the greatest increase in preterm infants. Whole blood viscosity decreased by about $10 \%$ in all three groups because of a similar reduction in hematocrit. Red blood cell aggregation decreased by about $20 \%$ after IL infusion. Blood pressure rose by $10 \%$, and peripheral blood flow declined by about $10 \%$ in the three groups. Vascular hindrance, a calculation of blood pressure divided by blood flow and viscosity, was raised by about $20 \%$, suggesting marked vasoconstriction of peripheral arteries. Vasoconstriction rather than hemorheological changes during infusion of IL may play a crucial role in the pathogenesis of circulatory alterations in parenterallyfed neonates.
\end{abstract}

Keywords Children · Circulation · Hemorheology · Intralipid $\cdot$ Newborn

U. Kessler $\cdot$ Z. Zachariou

Department of Surgical Pediatrics,

University of Bern Inselspital, 3010 Bern, Switzerland

U. Kessler $(\bowtie) \cdot$ D. Raz $\cdot$ J. Poeschl $\cdot$ O. Linderkamp

Division of Neonatology, Department of Pediatrics,

University of Heidelberg, Im Neuenheimer Feld 153,

69120 Heidelberg, Germany

E-mail: ulf.kessler@insel.ch

Fax: + 41-31-6329292

\section{Introduction}

Intravenous lipid emulsions of soybean triglycerides, such as Intralipid (IL), are principally given to prevent deficiency of essential fatty acids, to supply the necessary calories for energy expenditure and growth, and to improve the support of fat-soluble vitamins in patients of all ages, including newborn infants.

Besides various metabolic side effects of fat emulsions in neonates, several papers report pulmonary complications in preterm infants as a result of IL infusion, including fat embolism [1, 2], increased pulmonary vascular resistance [3, 4], increased alveolar-arteriolar oxygen gradient [5], and increased risk of bronchopulmonary dysplasia [6,7]. These observations have been connected with lipid accretion in pulmonary microvessels [2] and with several mechanisms that influence microcirculation, such as lipid peroxide production [8], increased production of prostaglandins and thromboxane $[9,10]$, and diminished bioavailability of the endothelium-derived vascular relaxant NO [11]. Thus, a relationship between IL infusion and microcirculatory deterioration in neonates seems probable, although clinical impact and mechanisms remain unclear.

In healthy adults, IL infusion has resulted in a marked rise in systolic arterial blood pressure [12] and peripheral [12] and systemic [13] vascular resistance. It has been suggested that alterations of hemorheological properties through hypertriglyceridemia caused by IL may be a causative factor in the rise of peripheral resistance.

An increase in either vascular reactivity or blood viscosity caused by a fast rise in plasma triglycerides may contribute to the circulatory effects of IL infusions according to the Hagen-Poiseuille law [14]. There are only few and partially differing results about the effects of IL infusion on blood viscosity and its determinants plasma viscosity, red blood cell (RBC) aggregation, and RBC deformability [15-17].

In preterm and small-for-gestational-age newborns, intravenous fat elevates the concentrations of triglyce- 
rides and free fatty acids significantly more than in fullterm neonates, children, or adults [18, 19]. These findings prompted us to determine blood viscosity and its determinants (hematocrit, plasma viscosity, and RBC aggregation and deformabililty) as well as vascular hindrance in preterm newborns, fullterm neonates, and children before and after IL infusion.

\section{Patients and methods}

\section{Patients and blood samples}

Effects of parenterally administered IL were studied in 10 preterm infants (gestational age 26-32 weeks, birth weight 1,000-2,300 g), 10 fullterm neonates (gestational age 38-41 weeks, birth weight 2,900-3,600 g), and 10 children (age 0.5-12 years). Excluded were infants and children with signs of septicemia, arterial hypotension, pulmonary hypertension, or cardiac or renal disease, as well as infants and children with serum bilirubin $>12 \mathrm{mg} / \mathrm{dl}$ or inspiratory oxygen $>40 \%$. None was being treated with sedatives, analgesics, diuretics, or vasoactive drugs. In the preterm and fullterm neonates, IL was started at 48-72 $\mathrm{h}$ of postnatal age because they had not tolerated oral feeding since birth. The children were given IL because they had not tolerated oral feeding 48-72 h after an operation. All infants and children were studied immediately before and after they received an initial total dose of $6 \mathrm{ml} / \mathrm{kg}$ of IL $10 \%$ over $4 \mathrm{~h}$. Blood samples were taken before and at the end of the infusion.

\section{Hemodynamic measurements}

Bilateral calf blood flow was measured by venous occlusion plethysmography using calibrated mercury in silastic strain gauges. Blood pressure was assessed via oscillometry (Dinamap Pro Monitor 300, Criticon, Tampa, USA). In plethysmography and in blood pressure measurements, an average of five recordings was used for analysis.

\section{Hematologic methods}

Hematocrit was determined by a micro-hematocrit method. The values were corrected for $2 \%$ of trapped plasma. RBC count, hemoglobin concentration, and white cell count were determined using a Coulter Counter (Coulter Electronics, Harpenden, Herts, UK). Total plasma protein concentration was measured by the Biuret test. Plasma fibrinogen, immunoglobulin G, and albumin concentrations were determined via radialimmunodiffusion techniques (M-Partigen kits, Behring, Marburg, Germany).
Hemorheological methods

All hemorheological measurements were made within $1 \mathrm{~h}$ after blood collection. Blood and plasma viscosities were determined by means of a capillary viscometer [20]. A tube with a diameter of $100 \mu \mathrm{m}$ and length of $1 \mathrm{~cm}$ was perfused with whole blood and plasma at a temperature of $37^{\circ}$ and a pressure of $25 \mathrm{~cm} \mathrm{H}_{2} 0$. Blood and plasma viscosities (11) were calculated from the passage times of the samples (ts) and distilled water $\left(\mathrm{tH}_{2} \mathrm{O}\right)$ and from the viscosity of water at $37^{\circ}(0.6915 \mathrm{mPas})$ :

$\eta=\left(\mathrm{ts} / \mathrm{tH}_{2} \mathrm{O}\right)(0.6915)$.

Relative viscosity was calculated as ratio of blood to plasma viscosity.

$\mathrm{RBC}$ aggregation was assessed at $22^{\circ} \mathrm{C}$ using the Myrenne Erythrocyte Aggregometer MA2 (Myrenne, Roetgen, Germany), which consists of a transparent cone plate viscometer [21]. A blood sample with an adjusted hematocrit of $40 \%$ is sheared for $20 \mathrm{~s}$ to disperse all RBC aggregates. The drive motor is then stopped, and the light transmission increases with time at a rate proportional to the rate of $\mathrm{RBC}$ aggregation. The increase in light transmission during $20 \mathrm{~s}$ of blood stasis is measured and displayed as an aggregation index.

The deformability of single RBCs was observed and measured at $22^{\circ} \mathrm{C}$ using a counter-rotating, cone-plate rheoscope [22] (Effenberger Munich, Germany), which was mounted on an inverted microscope (Leitz Diavert, Wetzlar, Germany). Six shear stresses from 6 to 85 dyn/ $\mathrm{cm}^{2}$ were applied, and microphotographs of the cells were taken at each of the shear stresses. Deformation results in elongation of the RBC, and deformation $(D)$ is defined as $0=(L-W) /(L+W)$, where $L$ is the length and $W$ the width of the deformed cell. To achieve shear stresses causing marked RBC deformation, $5 \mu \mathrm{l}$ of blood were diluted 1:50 in a dextran solution with a viscosity of $21 \mathrm{mPas}$ (centipoise).

\section{Statistical evaluation}

A paired $t$-test was used to analyze differences between values before and after IL administration within each group. The magnitude of changes produced by IL in the different groups was compared using an unpaired $t$-test. A value of $P<0.05$ was considered significant. Data are presented as mean \pm standard error of the mean (SEM) unless otherwise specified.

\section{Ethics}

The studies were conducted according to the Helsinki Declaration and approved by the Ethical Committee of the Department of Pediatrics of the University of Heidelberg. The parents of all infants and children gave their informed consent. 


\section{Results}

Several differences in hemorheological parameters before IL infusion were noted among preterm infants, fullterm neonates, and children: blood viscosity, plasma viscosity, and $\mathrm{RBC}$ aggregation were lower in preterm infants than in fullterm neonates and reached the highest values in children (Figs. 1 and 2 and Table 1). As previously reported, these observations can be related to differences in total plasma protein and fibrinogen concentrations $[20,21,23]$. The deformability of RBCs studied by means of a rheoscope did not differ among the various groups (Fig. 1).

The results of the measured parameters before and after IL infusion are given in Table 1 and Fig. 1. Basal serum triglyceride levels were lower in neonates than in children. After IL infusion, the highest rise in triglyceride levels was observed in preterm infants. Hemoglobin concentration and hematocrit decreased by about $7 \%$, blood viscosity fell by about $10 \%$, and RBC aggregation fell by $20 \%$ (Fig. 1). No significant changes were noted in total plasma protein, plasma albumin, immunoglobulin $\mathrm{G}$, fibrinogen, $\mathrm{MCV}, \mathrm{MCH}, \mathrm{MCHC}$, plasma viscosity, $\mathrm{RBC}$ deformation, or blood viscosity at constant hematocrit of 0.45 (Table 1 and Fig. 1). IL infusion significantly elevated blood pressure in fullterm neonates and children (from $542 \pm 7$ to $592 \pm 8 \mathrm{mmHg}$ in fullterm neonates, $P<0.05$, and from $732 \pm 10$ to $782 \pm 11 \mathrm{mmHg}$ in children, $P<0.05)$. A slight rise in blood pressure of preterm infants was not shown to be significant (Fig. 2). Although reduction of peripheral blood flow was not significant in any of the three groups, a significant elevation of peripheral resistance (from $4.72 \pm 0.6$ to $5.22 \pm 0.7 \mathrm{mmHg} / \mathrm{ml} / \mathrm{min} 100 \mathrm{ml}$ in preterm infants, $P<0.05$, from $6.62 \pm 0.9$ to $7.22 \pm 1.2 \mathrm{mmHg} / \mathrm{ml} /$ min $100 \mathrm{ml}$ in fullterm neonates, $P<0.05$ and from $13.82 \pm 1.9$ to $15.22 \pm 2.4 \mathrm{mmHg} / \mathrm{ml} / \mathrm{min} 100 \mathrm{ml}$ in fullterm neonates, $P<0.05$ ) and of vascular hindrance, calculated as the ratio of resistance to blood viscosity $(\mathrm{R} /$ $\mathrm{BV}$ ) (from $2.22 \pm 0.3$ to $2.82 \pm 0.5 \mathrm{R} / \mathrm{BV}$ in preterm infants, $P<0.05$, from $2.2 \pm 0.4$ to $2.92 \pm 0.6 \mathrm{R} / \mathrm{BV}$ in fullterm neonates, $P<0.05$ and from $5.42 \pm 1.0$ to $6.32 \pm 0.9 \mathrm{R} / \mathrm{BV}$ in children, $P<0.05$ ) was found.

\section{Discussion}

In agreement with previous studies, we observed that whole blood viscosity at given hematocrit, plasma viscosity, and $\mathrm{RBC}$ aggregation were lower in preterm infants than in fullterm neonates and lower in fullterm neonates than in children and adults. These differences have been related to lower plasma proteins in neonates compared with adults [20, 21, 23, 24]. Plasma viscosity is strongly dependent on total plasma protein concentration, but it is more influenced by macroproteins as fibrinogen than by smaller proteins as albumin. Aggregation of RBCs is entirely dependent on the concentra-

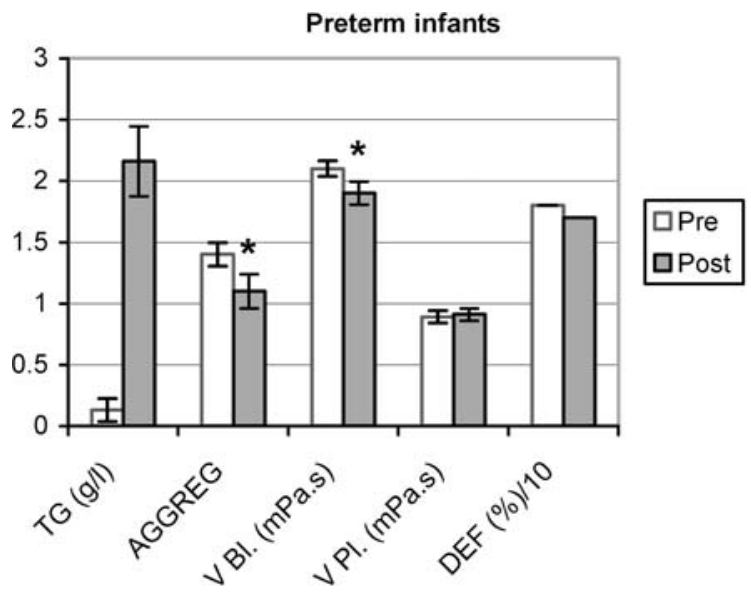

Full-term neonates
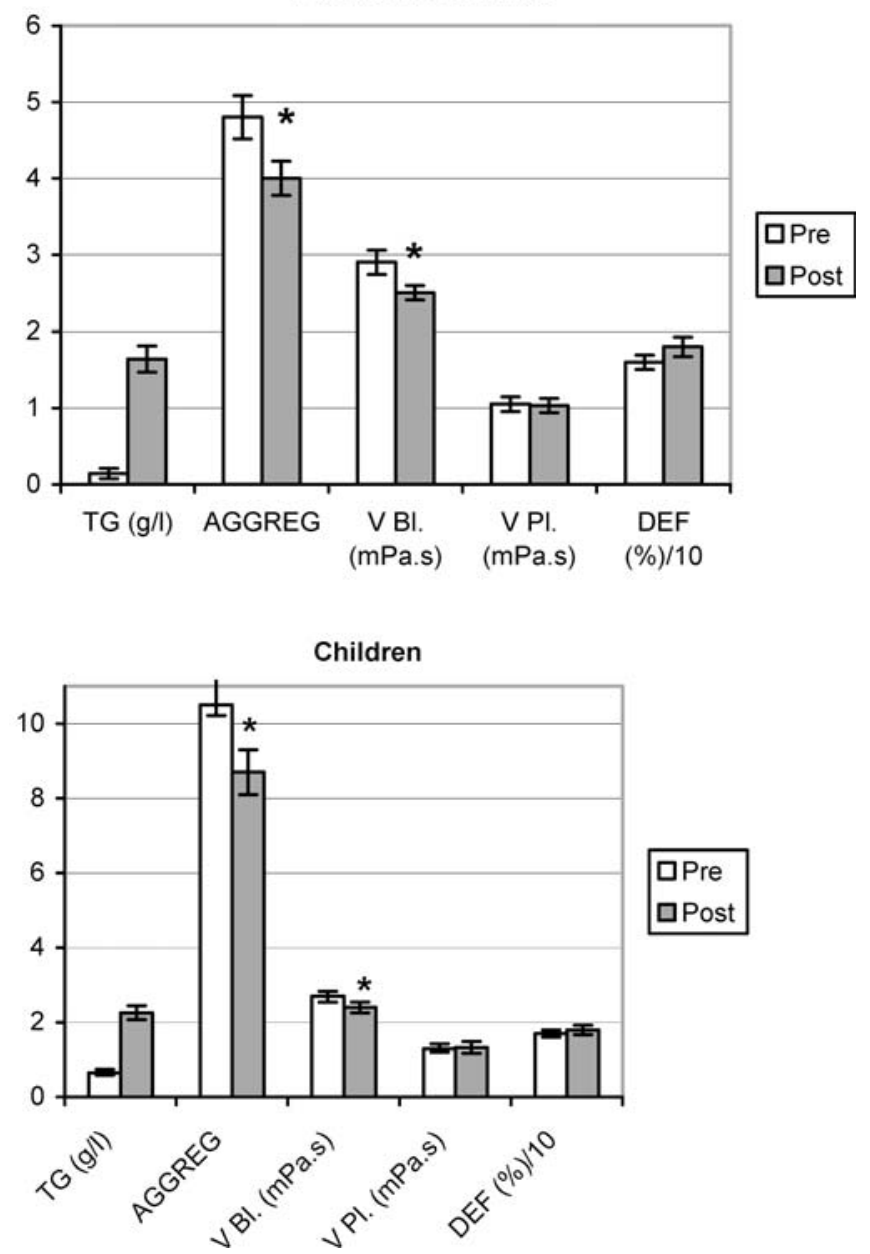

Fig. 1 Effects of Intralipid infusion $(0.6 \mathrm{~g} / \mathrm{kg}$ over $4 \mathrm{~h})$ on hemorheologic parameters

tion of macroproteins forming bridges among adjacent $\operatorname{RBC}[21,24]$. Thus, the steady increase of macroproteins with gestational and postnatal age explains the concomitant rise in $\mathrm{RBC}$ aggregation.

We found that IL infusion caused a marked decrease in $\mathrm{RBC}$ aggregation in children and neonates, whereas 
Table 1 Effects of Intralipid infusion $(0.6 \mathrm{~g} / \mathrm{kg}$ over $4 \mathrm{~h})$ on hematologic parameters

\begin{tabular}{|c|c|c|c|c|c|c|}
\hline & \multicolumn{2}{|c|}{ Preterm infants } & \multicolumn{2}{|c|}{ Fullterm neonates } & \multicolumn{2}{|l|}{ Children } \\
\hline & Pre & Post & Pre & Post & Pre & Post \\
\hline Plasma triglycerides $(\mathrm{g} / \mathrm{l})$ & $0.13 \pm 0.09$ & $2.16 \pm 0.22$ & $0.14 \pm 0.07$ & $1.64 \pm 0.17$ & $0.65 \pm 0.1$ & $2.26 \pm 0.19$ \\
\hline Hemoglobin $(\mathrm{g} / \mathrm{dl})$ & $15.3 \pm 0.5$ & $14.2 \pm 0.5$ & $16.4 \pm 0.6$ & $14.8 \pm 0.4^{*}$ & $12.5 \pm 0.3$ & $11.8 \pm 0.25$ \\
\hline Hematocrit $(\%)$ & $0.46 \pm 0.02$ & $0.43 \pm 0.02$ & $50 \pm 0.02$ & $0.46 \pm 0.02 *$ & $0.39 \pm 0.01$ & $0.37 \pm .01$ \\
\hline MCV (fl) & $120 \pm 2.8$ & $118 \pm 2.5$ & $108 \pm 1.9$ & $106 \pm 2.2$ & $91 \pm 1.3$ & $90 \pm 1.3$ \\
\hline $\mathrm{MCH}(\mathrm{pg})$ & $39 \pm 1.0$ & $38 \pm 1.0$ & $36 \pm 0.6$ & $35 \pm 1.0$ & $29 \pm 0.6$ & $29 \pm 1.0$ \\
\hline $\operatorname{MCHC}(\mathrm{g} / \mathrm{dl})$ & $33 \pm 0.63$ & $33 \pm 0.63$ & $33 \pm 0.63$ & $32 \pm 0.32$ & $32 \pm 0.32$ & $32 \pm 0.63$ \\
\hline Total plasma protein $(\mathrm{g} / \mathrm{l})$ & $48 \pm 1.3$ & $46 \pm 1.0$ & $53 \pm 1.9$ & $50 \pm 0.6$ & $72 \pm 2.5$ & $70 \pm 2.2$ \\
\hline Plasma fibrinogen $(\mathrm{g} / \mathrm{l})$ & $2.2 \pm 0.2$ & $2.1 \pm 0.2$ & $2.6 \pm 0.2$ & $2.4 \pm 0.2$ & $2.8 \pm 0.2$ & $2.6 \pm 0.2$ \\
\hline
\end{tabular}

Values are means $\pm \mathrm{SEM} ;{ }^{*} P<0.05$ when compared with basal values (paired $t$-test)
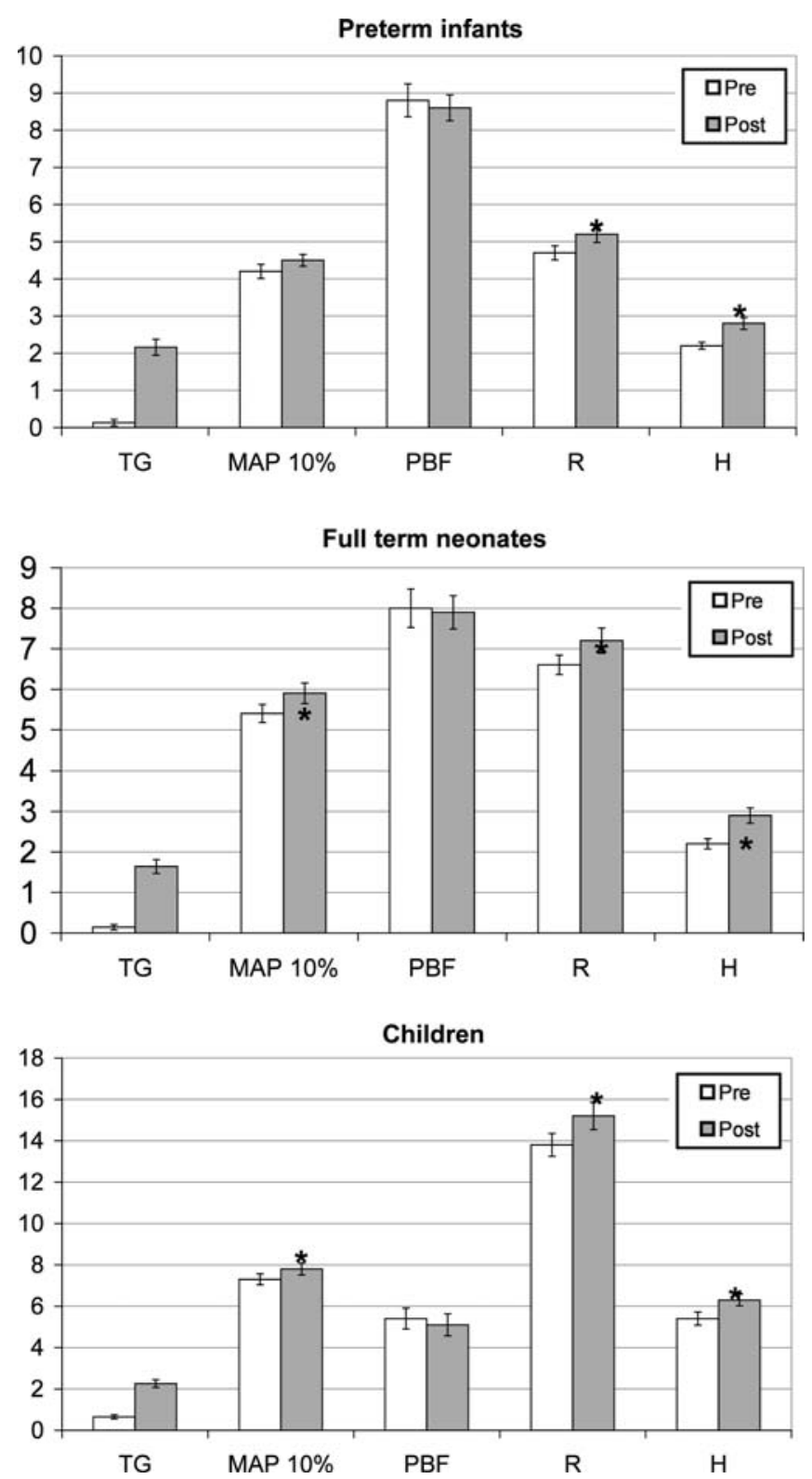

Fig. 2 Effects of Intralipid infusion for $3 \mathrm{~h}$ on circulatory parameters plasma viscosity and $\mathrm{RBC}$ deformation remained unchanged (Fig. 1). As we reported before, the decrease in $\mathrm{RBC}$ aggregation following in vitro incubation was strongly dependent on the IL concentration [25]. The in vitro addition of IL decreased plasma proteins by $1 \%$ $(1 \mathrm{mg} / \mathrm{ml})$ to $8 \%(8 \mathrm{mg} / \mathrm{ml})$. This decline in macroproteins could only partially explain the marked decrease of $\mathrm{RBC}$ aggregation. We have previously shown that a decrease in fibrinogen concentration of $8 \%$ reduces $\mathrm{RBC}$ aggregation by $22 \%$ in a fibrinogen range of $2-3 \mathrm{~g} / 1$ [21], whereas the decrease in RBC aggregation after the addition of IL at concentrations of $8 \mathrm{mg} / \mathrm{ml}$ decreased $\mathrm{RBC}$ aggregation in adults by $50 \%$ and abolished $\mathrm{RBC}$ aggregation in the neonates.

Effects of IL infusion on various rheological properties of blood in adults have recently been reported by Linde et al. [16]. Thirteen healthy adults received a bolus injection of $0.5 \mathrm{ml} / \mathrm{kg}$ of IL $20 \%$ in $10 \mathrm{~min}$ followed by an IL infusion of $90 \mathrm{ml} / \mathrm{h}$ over $4 \mathrm{~h}$, resulting in a total IL dose of approximately $0.4 \mathrm{~g} / \mathrm{kg}$.

Using a rotational viscometer, Linde et al. estimated $\mathrm{RBC}$ aggregation from measurements of whole blood viscosity at a low shear rate of $1 / \mathrm{s}$ and $\mathrm{RBC}$ deformability from viscosity measurements of RBCs suspended in buffer solution at a hematocrit of $55 \%$ and a shear rate of $1 / \mathrm{s}[16]$. They found a decrease in whole blood viscosity of $5 \%$, indicating a decrease in RBC aggregation, and a decrease in the viscosity of RBC buffer suspension of about $10 \%$ after IL infusion, suggesting an improvement of $\mathrm{RBC}$ deformability. In principle, the viscosity of RBCs suspended in a protein-free medium at given hematocrit is determined by RBC deformability only $[22,26]$. However, Linde et al. found no change in whole blood viscosity at a high shear rate of $1 / 100 \mathrm{~s}$ in hematocrit and plasma viscosity after IL infusion, although at constant hematocrit and plasma viscosity, increased RBC deformability should have decreased whole blood viscosity.

In contrast to the report of Linde et al. [15] and our results, Rim et al. found a significant positive correlation between whole blood viscosity (measured in a rotational viscometer at a shear rate of $7.34 \mathrm{~S}-1)$ and plasma triglyceride levels in dogs with hyperglyceridemia induced 
by IL infusion. It is unclear which of the determinants of blood viscosity (hematocrit, plasma viscosity, RBC deformability, or aggregation) was responsible for the triglyceride-dependent rise in blood viscosity, as only blood viscosity was reported.

The decrease in RBC aggregation after IL infusion may be explained by an increase in the RBC surface negativity [27], thereby increasing the repelling forces between RBCs. Moreover, fatty acids may compete with the binding sites of macroproteins on the RBC surface [28]. Our finding of normalization of RBC aggregation after resuspending RBCs in IL-free plasma indicates that IL decreased RBC aggregation as a result of direct effects of IL compounds on RBCs [25].

Effects of lipids on RBC deformability depend on the composition of the fatty acids. Docosahexaenoic acid has been shown to increase RBC deformability [29, 30]. IL contains little docosahexaenoic acid $(0.25 \%)$ and therefore does not increase RBC docosahexaenoic acid [30]. This may explain why IL had no effect on RBC deformability.

This is, to our knowledge, the first investigation to demonstrate elevated vasoconstriction after IL infusion in newborns. Vasoconstriction after IL infusion is known to occur in adults, mainly via an endotheliumdependent, still unclear mechanism [31]. Above that, blocking of endothelium-dependent vasorelaxation in adults has been shown to exclusively occur in the presence of heparin [31]. Our observations demonstrate that in newborns and children, mechanisms of vasoconstriction and dilation are different from those in adults.

We conclude that an initial infusion of IL at a dose of $0.6 \mathrm{~g} / \mathrm{kg}$ given in $4 \mathrm{~h}$ does not impair flow properties of blood, but it enhances peripheral vasoconstriction in neonates and children. RBC aggregation appears to decrease during IL infusion, suggesting improved blood flow properties at low shear forces (i.e., in veins). Previously described pulmonary side effects of IL as increasing pulmonary arterial pressure thus cannot be related to impaired flow properties of blood.

\section{References}

1. Skeie B, Askanazi J, Rothkope MM, Rosenbaum SH, Kvetan V, Thomashow B (1988) Intravenous fat emulsion and lung function: a review. Crit Care Med 16:83-193

2. Puntis JWL, Rushton DI (1991) Pulmonary intravascular lipid in neonatal necropsy specimens. Arch Dis Child 66:2628

3. Prasertsom W, Phillipos EZ, Van Aerde JE, Robertson M (1996) Pulmonary vascular resistance during lipid infusion in neonates. Arch Dis Child Fetal Neonatal Ed 74:95-98

4. Barrington KJ, Chan G, Van Aerde JE (2001) Intravenous lipid composition affects hypoxic pulmonary vasoconstriction in the newborn piglet. Can $\mathbf{J}$ Physiol Pharmacol 79:594-600

5. Brans YW, Dutton EB, Andrew OS, Menchaca EM, West DL (1986) Fat emulsion tolerance in very low birth weight neonates: effect on diffusion of oxygen in the lungs and on blood $\mathrm{pH}$. Pediatrics 78:79-84
6. Cooke RWI (1991) Factors associated with chronic lung disease in preterm infants. Arch Dis Child 66:776-779

7. Sosenko IRS, Rodriguez-Pierce M, Bancalari E (1993) Effect of early initiation of intravenous lipid administration on the incidence and severity of chronic lung disease in premature infants. J Pediatr 123:975-982

8. Pitkanen O, Hallman M, Andersson S (1991) Generation of free radicals in lipid emulsion used in parenteral nutrition. Pediatr Res 29:56-59

9. Haastrup AT, Gadegbeku CA, Zhang O, Mukhin YV, Greene EL, Jaffa M, Egan BM (2001) Lipids stimulate the production of 6-keto-prostaglandin Fla in human dorsal hand veins. Hypertension 38:858-863

10. Stepniakowski KT, Lu G, Davda RK, Egan BM (1997) Fatty acids augment endothelium-dependent dilation in hand veins by a cyclooxigenase-dependent mechanism. Hypertension 30:1634-1639

11. Davda RK, Stepniakowski KT, Lu G, Ullian ME, Goodfriend TL, Egan BM (1995) Oleic acid inhibits endothelial nitric oxide synthase by a protein kinase $\mathrm{C}$-independent mechanism. Hypertension 26:764-770

12. Paolisso G, Manzella O, Rizzo MR, Ragno E, Barbieri M, Varricchio G, Varricchio M (2000) Elevated plasma fatty acid concentrations stimulate the cardiac autonomic nervous system in healthy subjects. Am J Clin Nutr 72:723-730

13. Stepniakowski KT, Goodfriend TL, Egan BM (1995) Fatty acids enhance vascular and adrenergic sensitivity. Hypertension 25:774-778

14. Linderkamp O (1996) Pathological flow properties of blood in the fetus and neonate. Clin Hemorheol16:105-116

15. Rim SJ, Leon-Poi H, Lindner JR, Wei K, Fisher NG, Kaul S (2001) Decrease in coronary blood flow reserve during hyperlipidemia is secondary to an increase in blood viscosity. Circulation 104:2704-2709

16. Linde T, Sandhagen B, Fugman A, Lithell H, Berne C, Lind L (2000) Improved hemorheological properties during infusion of a lipid emulsion (lntralipid) in healthy subjects. Intensive Care Med 26:1462-1465

17. Bergentz SE, Gelin LE, Rudenstam CM (1960) Intravascular aggregation of blood cells following intravenous infusion of fat emulsions. Acta Chir Scand 120:115

18. Brans YW, Andrew OS, Carrillo OW, Dutton EB, Menchaca EM, Puelo-Scheppke BA (1990) Tolerance of fat emulsions in very low birthweight neonates: effect of birthweight on plasma lipid concentrations. Am J Perinatol 7:114-117

19. Ruben S, Kleinfeld AM, Richeiri GV, Hiatt M, Hegyi T (1997) Serum levels of unbound free fatty acids. II: The effect of intralipid administration in premature infants. J Am Col Nutr 16:85-87

20. Linderkamp O, Stadler A, Zilow EP (1992) Blood viscosity and optimal hematocrit in preterm and full-term neonates in 50- to 500-1 Jm tubes. Pediatr Res 32:97-102

21. Linderkamp O, Ozanne P, Wu PYK, Meiselman HJ (1984) Red blood cell aggregation in preterm and full-term neonates and adults. Pediatr Res 18:1356-1360

22. Linderkamp O, Guntner M, Hiltl W, Vargas VM (1986) Erythrocyte deformability in the fetus, preterm and term neonate. Pediatr Res 20:93-96

23. Linderkamp O, Nelle M, Kraus M, Zilow EP (1992) The effect of early and late cord-clamping on blood viscosity and other hemorheological parameters in full-term neonates. Acta Paediatr 81:745-750

24. Rampling MW, Whittingstall $P$, Martin G, Bignall S, Rivera RPA, Lissauer TJ, Bailey PC (1989) A comparison of the rheologic properties of neonatal and adult blood. Pediatr Res 25:457-460

25. Kessler U, Poeschl J, Raz O, Linderkamp O, Bauer J (2004) Effects of intralipid infusion on blood viscosity and other haemorheological parameters in neonates and children. Acta Paediatr 93:1058-1062

26. Reinhart WH, Oanoff SJ, King RG, Chien S (1985) Rheology of fetal and maternal blood. Pediatr Res 19:147-153 
27. Lapshina EA, Zavodnik IB, Bryszewska M (1995) Effect of free fatty acids on the structure and properties of erythrocyte membrane. Scand J Clin Lab Invest 55:391-397

28. Bojesen E, Bojesen IN (1982) A mean distance of more than 100 A separates the surfaces of lipoproteins and rat erythrocytes. Acta Physiol Scand 114:513-522

29. Poeschl JM, Leray C, Groscolas R, Ruef P, Linderkamp O (1996) Dietary docosahexaenoic acid improves red blood cell deformability in rats. Thromb Res 81:283-288

30. Smuts CM, Tichelaar HY, Kirsten GF, Dhansay MA, Faber M, van Jaarsveld PJ, Benade AJS (1998) The effect of paren- teral nutrition with Lipovenous or Intralipid on the fatty acid composition of plasma and erythrocyte membrane lipids in very low birthweight (VLBW) infants. SA J Clin Nutr 89:687694

31. Steer P, Millgard J, Basu S, Lithell H, Vessby B, Berne C, Lind L (2003) Vitamin C, diclophenac, and L-arginine protect endothelium-dependent vasodilation against elevated circulating fatty acid levels in humans. Atherosclerosis 168:65-72 